\title{
Design of Five Floors Elevator with SCADA System Based on S7200 PLC
}

\author{
Abdelkarim Ahmed Eltahir Ali ${ }^{1}$, Zhang Jiang Min ${ }^{2}$ \\ ${ }^{1,2}$ Tianjin University of Technology and Education (TUTE), School of Electronics Engineering Tianjin, China \\ ${ }^{2}$ Professor, Tianjin University of Technology and Education (TUTE), School of Electronics Engineering Tianjin, China
}

\begin{abstract}
This paper explains about design of five Floors Elevator with SCADA System Based on S7200 PLC.The elevator mentioned here is fully automated using PLC. The developed ladder logic has been implemented by Ladder diagram programming the required inputs and outputs of the elevator for moving forward and reverse, door opening and closing and motor operation have been included in the logic and interpreted in addition to that implementation of SCADA system Reduce waste time and improve the efficiency.
\end{abstract}

Keywords: PLC based elevator, Elevator Design, Constant speed Elevator, Ladder logic for Elevator using PLC

\section{Introduction}

Elevators are the important medium of vertical transportation in both residential environment and the industrial environment. Due to the cause of rapid population growth at the cities and multi-stored buildings, the need of elevators is being increased. With the rising life standards and attention to human and with the technological developments, elevator systems are getting better, more fast, stronger and better quality elevators are produced. Previously, most systems were focused on the mounting of elevators, especially after the 1980s the need for elevator maintenance and fault staff have been started to increase. For instance, automatic doors have being used instead of splash doors, microprocessor electronic cards have being used instead of cards with relay, double-speed or speedcontrolled elevators have being used instead of one-speed elevators. Such developments provide to improve the quality in elevator systems, develop and diverse the used setting and maintenance or repair tools and instruments and therefore facilitation of the work compared to previous years and increase the reliability of elevator.

Some of the drawbacks of the traditional system are the control system have high failure rate that were mainly due to numerous contacts, complexity of wiring circuit. In addition, electrical contacts were easy to burn out, which could result in poor contact.

Electrical controller and hardware wiring based on common method were difficult to achieve a more complex control function. Electromagnetic actuator and contact action were so slow, mechanical and electromagnetic have large inertia. Therefore; the control precision of system was difficult.

\section{Application of PLC for Control System}

The working principle of PLC for elevator control system functions in the similar manner as that the elevator we use in our daily life. The motion of the elevator that people normally use is controlled by three phases AC motors. It consists of a pulley which helps in upward and downward movement of the lift. The position feedback is provided by the limit switches. The principle of this set up is; whenever the cabinet is called to any floors the motor either runs in forward or reverse direction and then stop at the floor indicates. The indication of the floor position of the cabinet is given by the limit switches which act as a sensor and gives the signal indicating that the cabinet has reached the required position[1].

\section{Block Diagram}

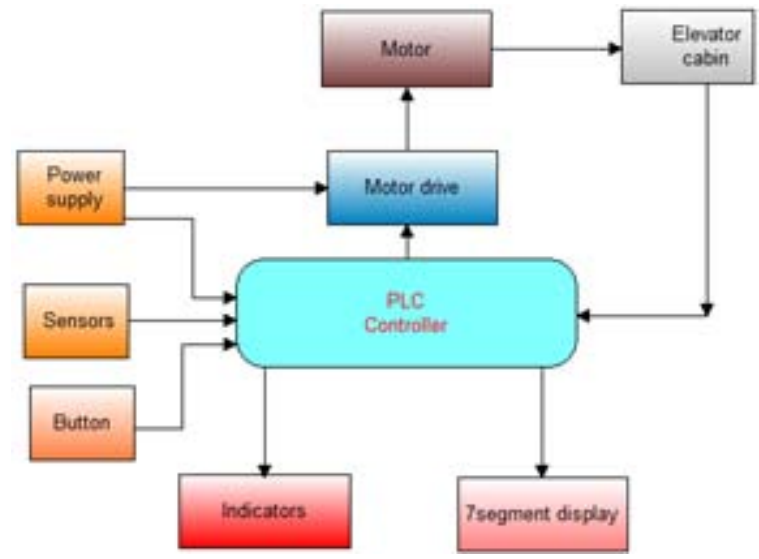

Figure1: Elevator block diagram

Fig.1 shows the overall system block diagram of this proposed system. The power supply is applied to both motor drive and the plc controller. Motor of the elevator is driven by the motor drive unit. The elevator cabin in turn driven by the motor unit. The elevator cabins upside and downside movement is controlled the switch operated motor. Theses witches are controlled by the PLC controller.

\section{Elevator Control System Components}

\subsection{Stepper Motor}

Stepper Motor is an electromagnetic device that converts digital pulses into mechanical shaft rotation. The advantages of step motors are low cost, high reliability, high torque at low speeds and a simple, rugged construction that operates in almost any environment. The disadvantages of a stepper motor is the resonance effect often exhibited at low speeds and decreasing torque with increasing speed. There are 


\section{International Journal of Science and Research (IJSR) \\ ISSN (Online): 2319-7064 \\ Index Copernicus Value (2013): 6.14 | Impact Factor (2015): 6.391}

basically three types of stepping motors; variable reluctance, permanent magnet and hybrid. They differ in terms of construction based on the use of permanent magnets and iron rotors with laminated steel stators. The motor used for the development of the set-up is permanent magnet type. The permanent magnet motor, also referred to as a "cans tack" motor, as the name implies, a permanent magnet rotor. It is a relatively low speed, low torque device with large step angles of either 45 or 90 degrees [4].

\subsection{Stepper drives M542}

M542 is a low cost high performance micro stepping driver based on most advanced technology in the world today. It is suitable for driving any 2-phase and 4-phase hybrid step motors. By using advanced bipolar constant-current chopping technique, it can output more speed and power from the same motor, compared with traditional technologies such as L/R drivers. Its 3-state current control technology allows coil currents to be well controlled, with relatively small current ripple and therefore less motor heating.[10]

\subsection{Inductive Proximity Sensor}

Inductive proximity switches are used to detect the presence of the elevator without actually contacting. Their high-speed switching and small size make them indispensable in automation applications. Inductive proximity switches consist of a coil driven by an oscillator. The oscillator creates an electromagnetic field which appears at the active face of the switch. If a metal target enters this area, the electromagnetic field is reduced and the switch turns on or off.

\subsection{Buttons}

Hall buttons are on a panel on the outside of the elevator shafts and are used by potential passengers to call an elevator cab to the floor that the pressed summon button is located on. Floor request buttons are particular elevator controller will be controlling elevator cabs that are in a building with 5 floors. Consequently, each cab has 5 floors request buttons labeled 1 through 5 that passengers can use to direct the elevator cabs to the floor that they would like to go to. There is button on the interior panel of each cab. A passenger can press this button to open the elevator doors or keep pressing it to keep them open, but only when the elevator cab is stopped at a floor [3].

\section{Problems to be solved through ladder diagram}

Ladder diagram is used to realize the many functionalities of the elevator control system. Some of the functionalities are, program should be written to make the display on which indicates the upward or downward movement, the door of the elevator should be programmed to open and close automatically. When the elevator has no request it remains at its current floor with its door closed floor lamp should glow within the lift to indicate the current position. As shown in fig.2 The main application of PLC is in the signal control system, all the control signals are realized using the PLC, the input signals are operational modes, safety control signals, car-calls, hall-calls, floor sensors, leveling sensors, door opening and close signals.

All the functions of the elevator control systems are realized using the PLC programs, the functions includes registration, displaying the messages about the floors, monitoring the safety system, monitoring the door opening and closing, prioritizing the hall call, and car calls. Fig.1 indicates the block diagram of the signal control system. The inputs are given to the PLC unit where the corresponding outputs like floor lamps, hall call lamps, direction lamps, door open and close lamps are introduced.

As an initial move the ladder logic has to be developed for receiving the input signal from the call buttons [5] 


\section{International Journal of Science and Research (IJSR) \\ ISSN (Online): 2319-7064}

Index Copernicus Value (2013): 6.14 | Impact Factor (2015): 6.391

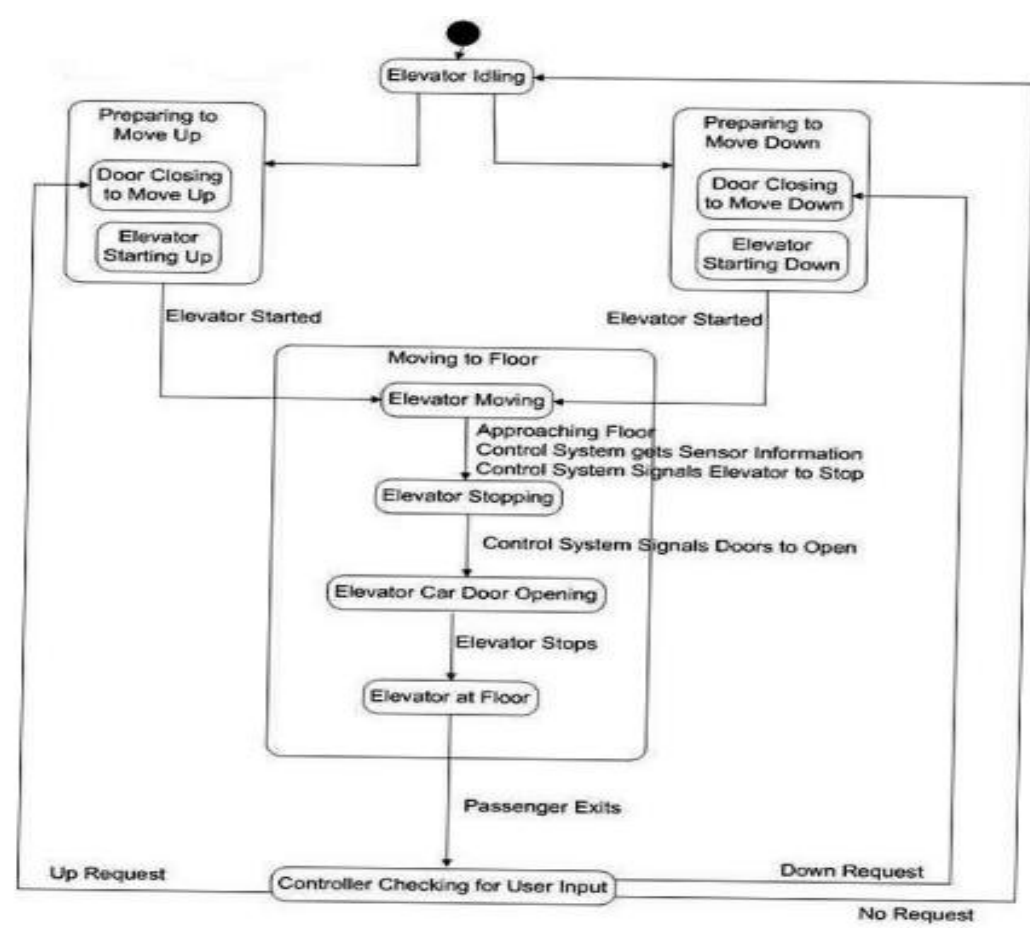

Figure 2: Elevator flow chart

Elevator System is the system responsible for coordinating all aspects of elevator service such as travel, speed, and accelerating, decelerating, door opening speed and delay, leveling and hall lantern signals. It accepts inputs (button signals and sensors etc.) and produces outputs (elevator cars moving, doors opening, etc.).Fig.3 shows the elevator control system and corresponding connection to the PLC.

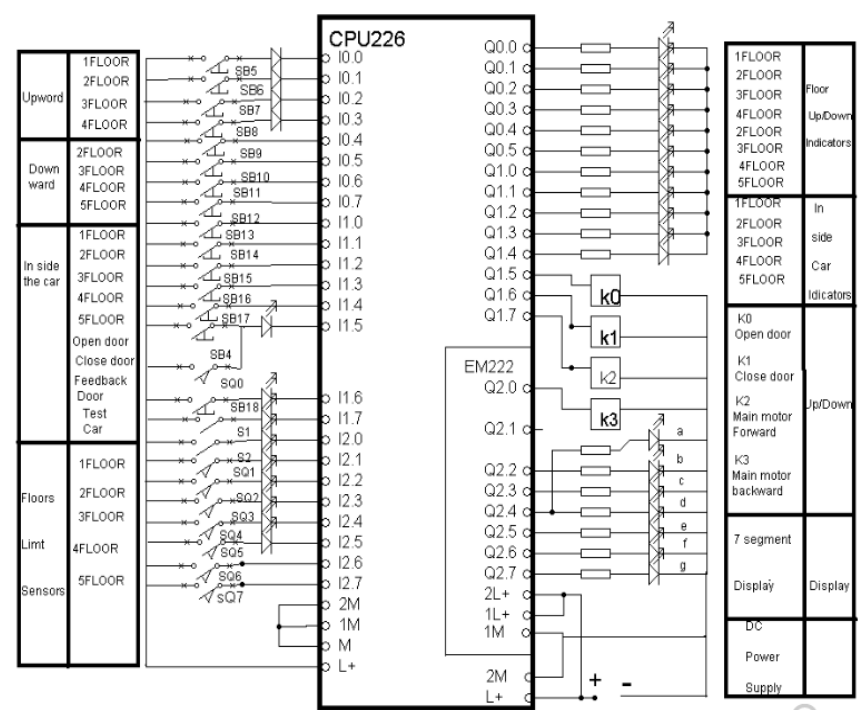

Figure 3: Elevator PLC Connections

\section{The Aim of an Elevator Control System}

The main aims of the elevator control system are:

- To bring the lift car to the correct floor.

- To minimize travel time.

- To maximize passenger comfort by providing a smooth ride.

- To accelerate, decelerate and travel within safe speed limits.
Table 1 show elevator ladder diagram inputs and the same is used with the program to get the corresponding output based on this input. Once the PLC receives the input signal the corresponding bit will be latched to activate the desired outputs as shows in Table 2.

Table 1: Elevator ladder diagram inputs

\begin{tabular}{|c|c|c|c|c|c|c|c|c|}
\hline component & Function & $\begin{array}{l}\text { First } \\
\text { floor }\end{array}$ & \multicolumn{2}{|l|}{$\begin{array}{l}\text { Second } \\
\text { floor }\end{array}$} & \multicolumn{2}{|c|}{ Third floor } & Fourth floor & Fifthfloor \\
\hline \multirow{5}{*}{$\begin{array}{l}\text { I } \\
\text { in put }\end{array}$} & $\begin{array}{l}\text { Push button } \\
\text { Manual button }\end{array}$ & $\begin{array}{l}10.0 \\
\text { Upward }\end{array}$ & \multicolumn{2}{|c|}{$\begin{array}{c}10.1 \\
\text { Downward }\end{array}$} & \multicolumn{2}{|c|}{$\begin{array}{c}10.2 \\
\text { LowSpeed }\end{array}$} & 10.3 & \\
\hline & Lowe call button & & \multicolumn{2}{|l|}{$\begin{array}{l}10.4 \\
\text { Stop }\end{array}$} & \multicolumn{2}{|c|}{10.5} & 10.6 & 10.7 \\
\hline & Inner button & 10.10 & \multicolumn{2}{|l|}{$\mid 1.1$} & \multicolumn{2}{|c|}{$\mid 1.2$} & 11.3 & 11.4 \\
\hline & limit switch & 12.1 & \multicolumn{2}{|l|}{12.2} & \multicolumn{2}{|c|}{12.3} & 12.4 & 12.5 \\
\hline & Other & $\begin{array}{l}\text { I1.5 } \\
\text { Door } \\
\text { open }\end{array}$ & $\begin{array}{l}\text { I1.6 } \\
\text { Door } \\
\text { close }\end{array}$ & $\begin{array}{l}\text { I1.7 } \\
\text { Manı } \\
\text { test }\end{array}$ & ually & $\begin{array}{l}\text { I2.0 } \\
\text { Car } \\
\text { position } \\
\text { feedback }\end{array}$ & \begin{tabular}{c|c}
12.6 \\
Dooropen \\
limit
\end{tabular} & \begin{tabular}{|l}
12.7 \\
Door \\
close \\
limit
\end{tabular} \\
\hline
\end{tabular}

Table 2: Elevator ladder diagram outputs

\begin{tabular}{|c|c|c|c|c|c|c|c|}
\hline component & Function & First floor & $\begin{array}{l}\text { Seco } \\
\text { floor }\end{array}$ & & Third floor & $\begin{array}{l}\text { Fourth } \\
\text { floor }\end{array}$ & Fifth floor \\
\hline \multirow{5}{*}{$\begin{array}{c}\text { Q } \\
\text { Out put }\end{array}$} & \begin{tabular}{|l|} 
Push button \\
indicators \\
Manual button \\
\end{tabular} & $\mathrm{Q} 0.0$ & \multicolumn{2}{|c|}{$\mathrm{Q} 0.1$} & $\mathrm{Q} 0.2$ & Q0.3.3 & \\
\hline & $\begin{array}{l}\text { Lowe call button } \\
\text { indicators }\end{array}$ & & \multicolumn{2}{|c|}{$\begin{array}{l}\text { Q0.4 } \\
\text { Stop }\end{array}$} & Q0.5 & Q0.6 & Q 0.7 \\
\hline & $\begin{array}{|ll|}\text { Inner } & \text { button } \\
\text { indicators } & \end{array}$ & Q1.0 & \multicolumn{2}{|c|}{ Q1.1 } & Q1.2 & Q1.3 & Q1.4 \\
\hline & control & $\begin{array}{l}\text { Q1.5 } \\
\text { Dooropen }\end{array}$ & \multicolumn{2}{|c|}{$\begin{array}{c}\text { Q1.6 } \\
\text { DoorClose }\end{array}$} & $\begin{array}{l}\text { Q1.7 } \\
\text { Upward }\end{array}$ & $\begin{array}{c}\text { Q2.0 } \\
\text { Downward }\end{array}$ & \begin{tabular}{l|l} 
Q2.1 \\
d & LowSpeed
\end{tabular} \\
\hline & Other & $\begin{array}{c}\text { Q2.2 } \\
\text { B } \\
\text { 7-display }\end{array}$ & $\begin{array}{c}\text { Q2.3 } \\
\text { C } \\
\text { 7-disay }\end{array}$ & \begin{tabular}{|c|} 
Q2.4 \\
D \& A \\
7-display
\end{tabular} & $\begin{array}{c}\text { Q2.5 } \\
\text { E } \\
\text { 7-display }\end{array}$ & $\begin{array}{c}\text { Q2.6 } \\
\text { F } \\
\text { 7-display }\end{array}$ & $\begin{array}{c}\text { Q2.7 } \\
\text { G } \\
\text { 7-display }\end{array}$ \\
\hline
\end{tabular}




\section{International Journal of Science and Research (IJSR) \\ ISSN (Online): 2319-7064}

Index Copernicus Value (2013): 6.14 | Impact Factor (2015): 6.391

\section{Hall Call Request}

There are two kinds of calls in the elevator they are hall call and car call. When the passenger presses the button in the control panel which is outside the elevator cabin that is the hall call. When the passenger presses the button on the control panel which is inside the elevator car that is the car call. As shown below fig. 4 .This ladder program branch control the User from 1 to 4 floors, when the user press the button sends out the down signal to inform the PLC to control the elevator to run to the floor where the passenger at

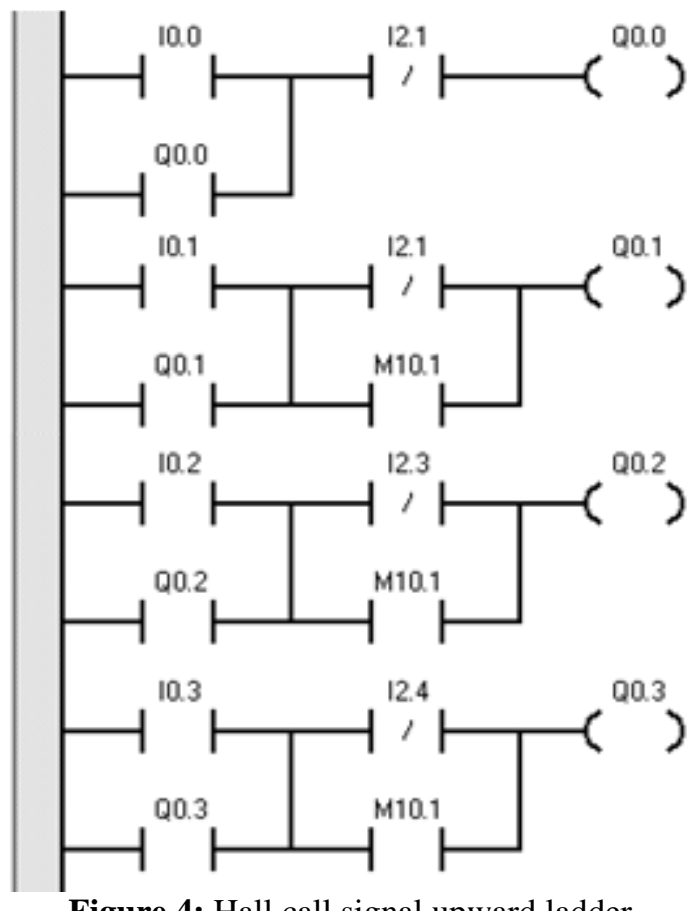

Figure 4: Hall call signal upward ladder

The below ladder program branch control the passenger from 2 to 5 floors, when the passenger press the button sends out the up request signal to inform the PLC to take the elevator for the floor where the passenger at .

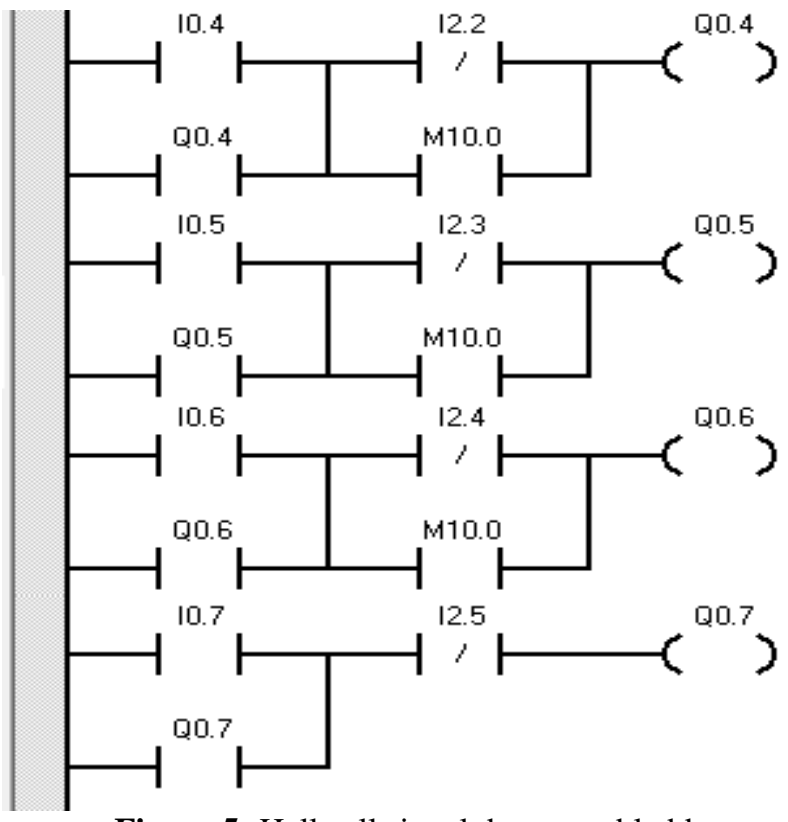

Figure 5: Hall call signal downward ladder

\section{Up and down control signal identification}

Fig.6 shows ladder diagram indicates the up moving or down of the elevator. The combination of hall call and car calls are used to decide the elevator movement in upward or downward direction. If the current position of the elevator is less than the first element of the queue then the elevator will move in the upward direction.

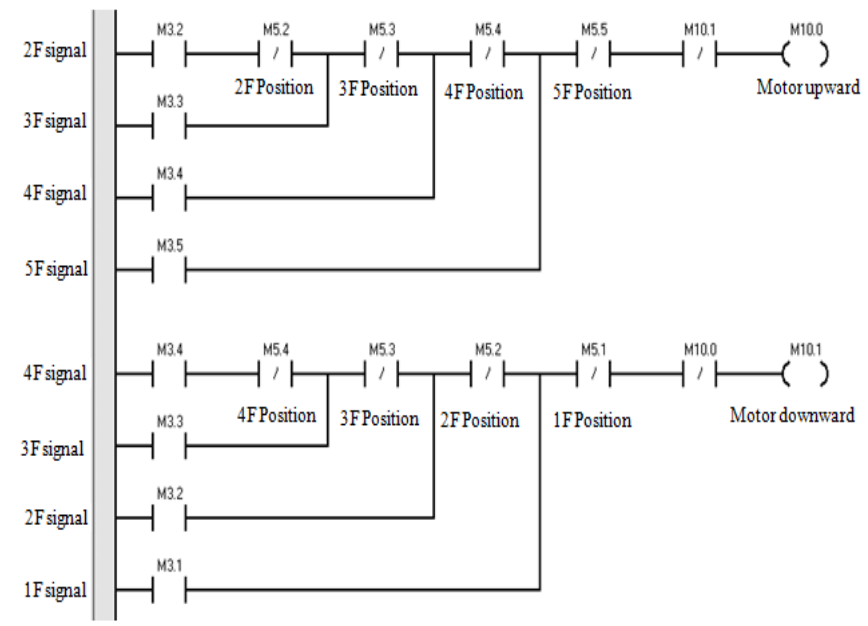

Figure 6: Elevator upward downward identification signal

\section{Seven Segment Display Logic Design}

The car position is displayed using seven segments display the interior of each elevator cab has a display that indicates to its passengers which floor the elevator cab is currently on. This system also has floor number display on every floor outside of the elevator doors. The controller interacts with this display by sending a signal that tells it which floor number to display as shown in Fig.7.

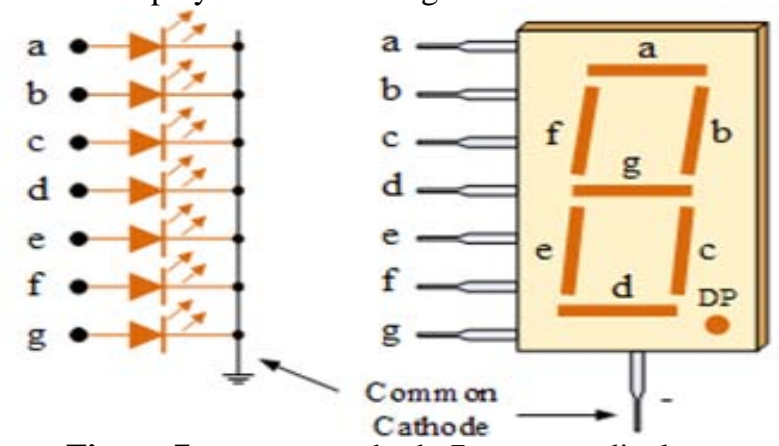

Figure 7:common cathode 7-segment display

\section{Seven Segment Display Logic Equation}
a, d: Q2.4=M5.2+M5.3+M5.5 $=\overline{\overline{\mathrm{M} 5.2} \cdot \overline{\mathrm{M} 5.3} \cdot \overline{\mathrm{M} 5.5}}$

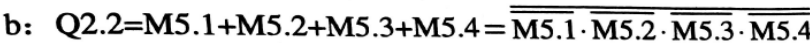
c: $\mathrm{Q} 2.3=\mathrm{M} 5.1+\mathrm{M} 5.3+\mathrm{M} 5.4+\mathrm{M} 5.5=\overline{\overline{\mathrm{M}} 5.1} \cdot \overline{\mathrm{M} 5.3} \cdot \overline{\mathrm{M} 5.4} \cdot \overline{\mathrm{M} 5.5}$
e: Q2.5=M5.2
f: $Q 2.6=M 5.4+M 5.5=\overline{\bar{M} 5.4 \cdot \bar{M} 5.5}$
g: $\mathrm{Q} 2.7=\mathrm{M} 5.2+\mathrm{M} 5.3+\mathrm{M} 5.4+\mathrm{M} 5.5=\overline{\mathrm{M} 5.2} \cdot \overline{\mathrm{M} 5.3} \cdot \overline{\mathrm{M} 5.4} \cdot \overline{\mathrm{M} 5.5}$ 


\section{International Journal of Science and Research (IJSR) \\ ISSN (Online): 2319-7064}

Index Copernicus Value (2013): 6.14 | Impact Factor (2015): 6.391

Table 3: Seven segment display outputs

\begin{tabular}{|l|l|l|l|l|l|l|l|l|l|}
\hline $\begin{array}{l}\text { Floor } \\
\text { position } \\
\text { switch }\end{array}$ & $\begin{array}{l}\text { Floor } \\
\text { memory } \\
\text { signal }\end{array}$ & $\begin{array}{l}\text { Floor } \\
\text { digital } \\
\text { display }\end{array}$ & $\begin{array}{l}\text { Q2.4 } \\
\text { A }\end{array}$ & $\begin{array}{l}\text { Q2.2 } \\
\text { B }\end{array}$ & $\begin{array}{l}\text { Q2.3 } \\
\text { C }\end{array}$ & $\begin{array}{l}\text { Q2.4 } \\
\text { D }\end{array}$ & $\begin{array}{l}\text { Q2.5 } \\
\text { E }\end{array}$ & $\begin{array}{l}\text { Q2.6 } \\
\text { F }\end{array}$ & $\begin{array}{l}\text { Q2.7 } \\
\text { G }\end{array}$ \\
\hline I2.1 & M5.1 & 1 & 0 & 1 & 1 & 0 & 0 & 0 & 0 \\
\hline I2.2 & M5.2 & 2 & 1 & 1 & 0 & 1 & 1 & 0 & 1 \\
\hline I2.3 & M5.3 & 3 & 1 & 1 & 1 & 1 & 0 & 0 & 1 \\
\hline I2.4 & M5.4 & 4 & 0 & 1 & 1 & 0 & 0 & 1 & 1 \\
\hline I2.5 & M5.5 & 5 & 1 & 0 & 1 & 1 & 0 & 1 & 1 \\
\hline
\end{tabular}

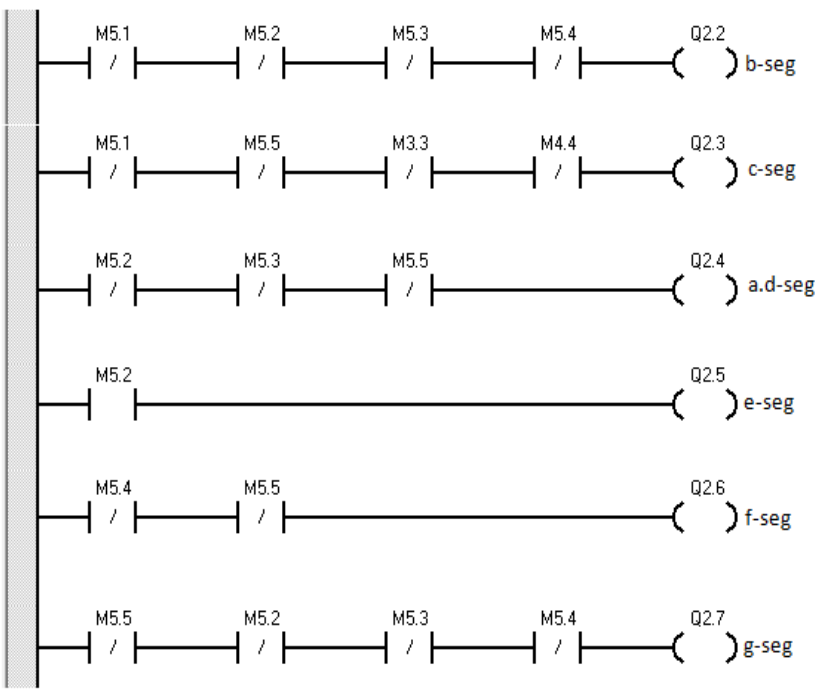

Figure 8: seven segment display ladder diagram

\section{Supervisory control and data acquisition systems (SCADA)}

In fig.6. Shows the SCADA system of the elevator it is the backbone of control and monitoring the systems in addition to that SCADA allows operators to.

- Monitor the elevator status.

- Interact with and control the elevator which is connected through HMI (human-machine interface) software which is developed for this purpose.

- Access history Record for maintenance and faults checking.

This SCADA system displays the elevator in order to help operators and other workers to reduce waste time and improve the efficiency.

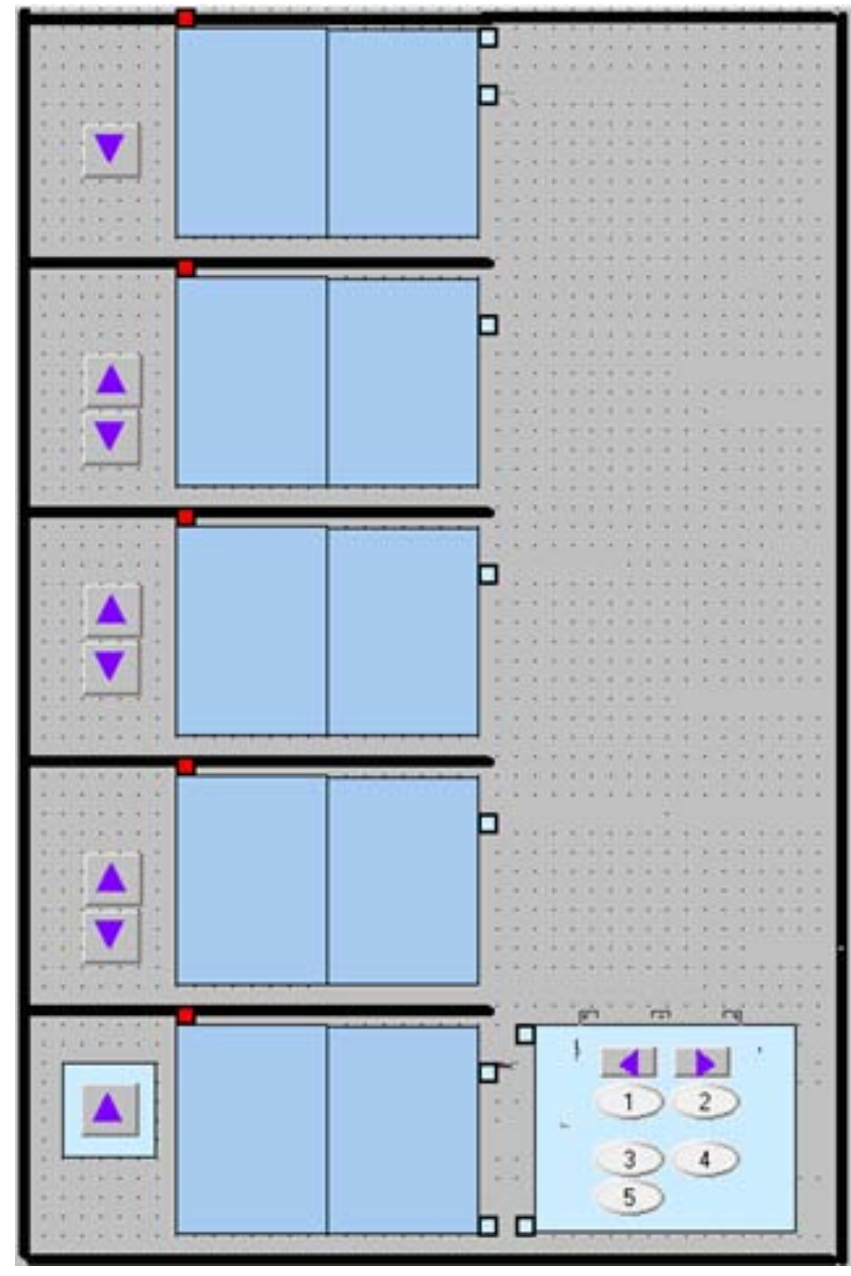

Figure 9: Elvator SCADA system

\section{Results and Discussion}

The interfacing between the S7200 PLC and the elevator done successfully in addition to that the SCADA system worked as per designed properly. When you push the button for the first floor is pressed then the motor runs till the cabinet reaches its required position and activates the limit switch which enables the motor to stop and if the cabinet is already in the required position then the motor won et get activated again when you push the button for the second floor is pressed then the motor runs either in forward or reversed condition according to its position till the cabinet reaches its required position and activates the limit switch which enables the motor to stop and if the cabinet is already in the required position then the motor will not get activated and subsequently it worked successfully for other floors too. 


\section{International Journal of Science and Research (IJSR) \\ ISSN (Online): 2319-7064 \\ Index Copernicus Value (2013): 6.14 | Impact Factor (2015): 6.391}

At the end using SCADA we can identify.

- Elevator faults easily.

- Control the elevator.

- Reduce waste time and improve the efficiency [7].

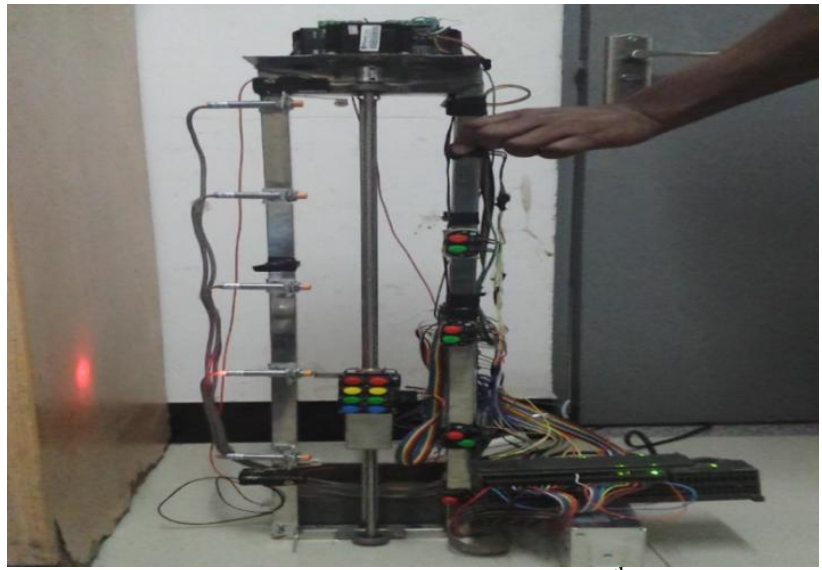

Figure 10: Passenger ordering on $5^{\text {th }}$ floor

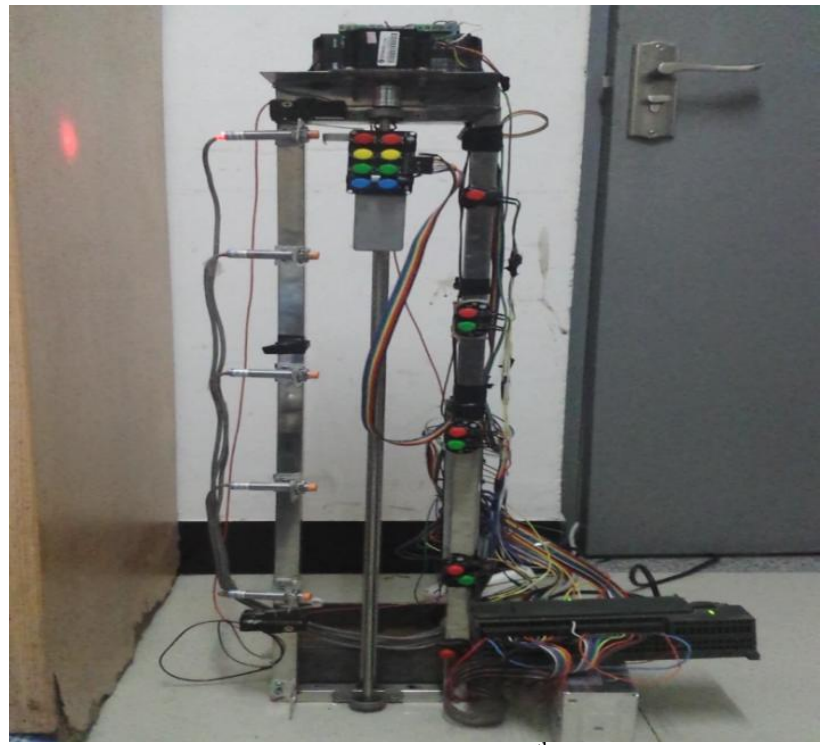

Figure 11: Elevator at $5^{\text {th }}$ floor

\section{Conclusion}

This paper describes implementation for five floors elevator with SCADA system using S7200 PLC also used sensors, buttons, actuators connection and their configuration at different floors.

The developed ladder logic has been implemented by Ladder diagram programming the required inputs and outputs of elevator for moving forward and reverse, door opening and closing and motor operation have been included in the logic and interpreted.

\section{References}

[1] Jack H., Programmable Logic Controller

[2] Yang X., Zhu Q., 1, Xu H., Design and Practice of an Elevator Control System Based on PLC

[3] http://www.electrical-knowhow.com/2012/04/elevatorcontrol-system.html
[4] userers Manual For M542-FL Low Cost Microstepping Driver Version 1.0 (C2000 All Rights Reserved

[5] Xialoling Yang, Qunxiong Zhu, Hong Xu,, "Design and practice of an elevator control system based on PLC", In proceedings of IEEE workshop on Power Electronics and Intelligent Transportation System, pp.94 - 992008

[6] Xiaojuan Liu, Development of Elevator Monitor System Based on the Fieldbus, February 2008

[7] KingView 6.52 Product Introduction

[8] Jie Zhang, "Application of PLC in elevator control system", Journal of Liaoning Normal University(Natural Science Edition), 2009.

[9] http://researchtrend.net/ijet61/7\%20NCRIET.pdf.[10]Da e-Woong Chung, Hyung-Min Ryu, Young-Min Lee, LoWon Kang, Seung-Ki Sul, Seok-Joo Kang, Jun-Ho Song, Joong-Seok Yoon, Kil-Haeng Lee and Jong-Ho Suh (2001) ,Drive systems for high-speed gearless elevators ${ }^{\text {ee }}$, IEEE Industry Applications Magazine, vol. 7, pp 52-56. 